\title{
Las torres conservadas en el territorio de Vélez-Málaga (Málaga)
}

The towers preserved in the territory of Vélez-Málaga (Málaga, Spain)

\section{Luis José García-Pulido a, Jonathan Ruiz-Jaramillo ${ }^{\text {b }}$}

${ }^{a}$ Laboratorio de Arqueología y Arquitectura de la Ciudad - Escuela de Estudios Árabes - Consejo Superior de Investigaciones Científicas, Granada / Departamento de Arte y Arquitectura - Universidad de Málaga, Málaga, Spain, luis.garcia@uma.es

b Departamento de Arte y Arquitectura - Universidad de Málaga, Málaga, Spain, jonaruizjara@uma.es

\begin{abstract}
The Spanish coast preserves many watchtowers as an important cultural heritage. They testify the insecurity of this maritime border in different historical periods, especially during the sixteenth and eighteenth centuries, when it was attacked regularly by what has come to be known as Berber piracy.

The territory of Vélez-Málaga was not alien to this process and, after the Castilian conquest of the $A x$ arquía region in the late fifteenth century, the western border between the Christian and the Islamic kingdoms of the western Mediterranean moved to the southeaster coast of the Iberian Peninsula.

The municipal district of Vélez-Málaga has an important architectural and archaeological heritage from different origins, including its defensive structures. They belong to a broader military system in the territory that consisted of coastal and inland watchtowers, farmstead towers, fortified enclosures in addition to the castle and the urban walls of Vélez-Málaga.

This paper presents the first data obtained from the diagnosis of this heritage in the frame of the programme of conservation of the defensive architecture from the municipality of Vélez-Málaga.
\end{abstract}

Keywords: Littoral municipal district, watchtower, farmstead tower, coastal surveillance.

\section{Introducción}

La actual provincia de Málaga abarca a grandes rasgos los cinco partidos más occidentales del reino de Granada, comenzando por el de la capital malagueña, junto al de Vélez-Málaga, las Cuatro Villas (Álora, Coín, Alhaurín el Grande y Cártama), Ronda y Marbella. Además, incluyó también la zona de Antequera, que, tras su temprana conquista en 1410, fue incluida inicialmente en el reino de Sevilla.

Esta división administrativa de carácter comarcal, que perduró hasta 1833, fue articulada tras la conquista castellana de estos territorios al englobar a los antiguos aqālìm nazaríes en un partido jurisdiccional en torno a un núcleo de población principal, correspondiente a una de las medinas del reino nazarí, seis en el caso que nos ocupa, las de Málaga, Vélez-Málaga, Álora, Ronda, Marbella y Antequera.

El partido de Vélez-Málaga llegó a ser mucho más amplio que su término municipal actual, abarcando 74912,447 ha, lo que supondría un 2,54\% de la superficie que ocupó el reino nazarí de Granada (Fig. 1). Abarcaba además una extensa franja costera de más de $50 \mathrm{~km}$ y otros tantos hacia el norte, hasta la Sierra de Tejeda, Almijara y Alhama. De dicho partido se habrían segregado en el siglo XIX los municipios que contaban con más de 1000 habitantes, creándose 
de este modo los términos de Alfarnate, Alfarnatejo, Periana, Alcaucín, Viñuela, Canillas de Aceituno, Seldella, Salares, Canillas de Albaida, Arenas, Archez, Cómpeta, Algarrobo, Torrox, Figiliana y Nerja.

\section{Arquitectura defensiva conservada en el partido de Vélez-Málaga}

El territorio asociado a Vélez-Málaga cuenta con un amplio muestrario de restos defensivos de distintas épocas históricas, que permiten adscribirlos a varias de las tipologías más representativas de entre las establecidas en la costa malagueña.

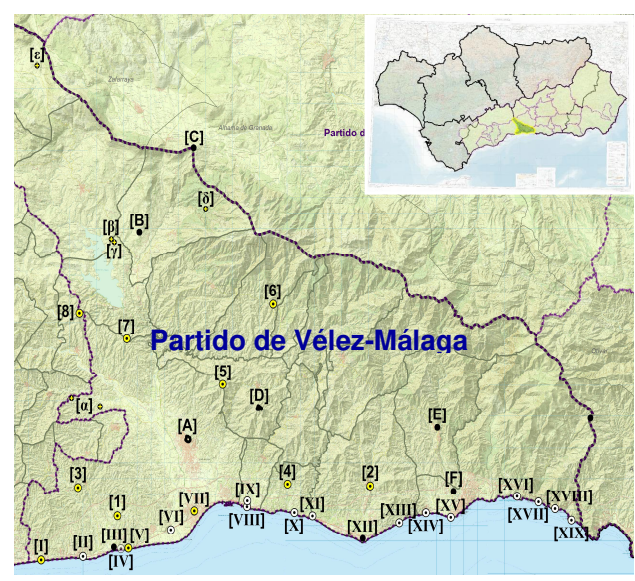

Fig. 1. Ubicación de las distintas fortificaciones conservadas en el partido de Vélez-Málaga, con la numeración entre corchetes referida en el texto (en amarillo y letras del alfabeto latino se señalan las torres con origen medieval y en blanco y con numeración latina las de época moderna). Con letras del alfabeto griego se posicionan los topónimos relativos a fortificaciones.

Las torres medievales conservadas ascienden a ocho, de las cuales al menos seis habrían estado vinculadas a alquerías, tales como las de Almayate Alto [1], la de Torrox [2], la del despoblado de Benadalid [3] y el conocido como Castillo de Lagos [4], del cual subsisten los restos de una torre con perímetro amurallado. La llamada torre mudéjar de Sedella [5] podría estar reutilizando la que hubiese existido en dicha alquería. La Torre del Cerro del Tambor [6], también podría haber estada vinculada a un poblamiento cercano, aun cuando, por su posición en altura, ejercía funciones de vigilancia y control territorial. A esta última categoría respondían la Torre del Cerro de la Atalaya Alta o de La Viñuela [7], y la del Cerro de la Torre [8] (Benamargosa), todas ellas en lugares elevados con vistas preminentes.

Entre las alcazabas y husșūn, se podrían señalar la de Vélez-Málaga [A], el Castillo de Zalía [B] (Alcaucín), el Castillo de Zafarraya [C] (en el límite provincial entre Málaga y Granada), el Castillo de Bentomiz [D] (Arenas), el Castillo de Frigiliana [E] y el Castillo de Nerja [F].

Además, se han conservado una serie de topónimos que podrían tener relación con la existencia de fortificaciones, tales como Atalayas Bajas $[\alpha]$, Casa de la Torrecilla Baja (La Viñuela/Periana) [ $\beta$ ], Cortijo de la Torrecilla de Ballesteros (La Viñuela) [ $\gamma$ ], Loma del Cortijo del

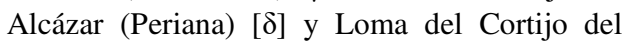
Castillejo (Alfarnate) $[\varepsilon]$.

Fueron muchas las fortificaciones establecidas en la Edad Moderna en esta amplia franja litoral, en total tres castillos costeros y 16 atalayas, algunas de las cuales ya existían en época nazarí, siendo transformadas tras la conquista cristiana. De oeste a este serían las siguientes: Torre de Chilches [I] (sobre una previa), Torre Moya [II], Castillo del Marqués [III], Torre del Peñón del Portichuelo o del Marqués [IV] (desaparecida), Torre del Jaral [V] (existencia previa), Torre de la Boca del Río Vélez o de Manganeta [VI], el Castillo de Torre del Mar [VII] (existencia previa), Torre Ladeada [VIII] (Algarrobo), Torre Derecha [IX] (Algarrobo) y Torre de Lagos [X] (estancia previa). Continuando hacia levante, en el término de Torrox había tres fortificaciones costeras, la Torre de Güi [XI], el Castillo Bajo de Torrox [XII] y la Torre de Calaceite [XIII] y seis en el término de Nerja: la Torre de Macaca [XIV], la Torre de Nerja [XV], la Torre de Maro [XVI], la Torre del Río de la Miel [XVII], la Torre del Pino [XVIII] y la Torre de la Caleta [XIX].

\section{La defensa de la franja costera de Vélez- Málaga}

La amplia extensión del litoral veleño se caracteriza por presentar una orografía muy cambiante, desde las ensenadas formadas por las desembo- 
caduras de ríos y ramblas, como los de VélezMálaga, Almayate o Lagos, a zonas de topografía abrupta como es el caso de los acantilados en torno a las torres del Jaral, Moya o Lagos. Las poblaciones constituidas por las antiguas alquerías andalusíes están diseminadas por los valles que tributan al río Vélez o que desembocan directamente en el Mediterráneo (Fig. 2), vinculadas a zonas de regadío por las posibilidades ofrecidas por un suministro de agua cercano. En general, están situadas a bastante distancia entre sí, y separadas por accidentes geográficos que dificultaban la conectividad física y visual entre ellas.

Este hecho permitía que las grandes ensenadas posibilitaran el embarque de mercancías y personas, pero también que el acceso no controlado a esta franja litoral se pudiese producir a través de otras calas más recónditas. Este hecho motivó que se creara toda una red de atalayas que pudiesen controlar estas áreas más vulnerables.

Tras la revuelta mudéjar acontecida en el reino de Granada hacia 1500, muchos andalusíes pasaron al norte de África, algunos de los cuales volvieron a cruzar el Mediterráneo con contingentes de asalto, dados sus conocimientos del territorio del que se habían exiliado. Tras ello se produjo una oleada de frecuentes desembarcos en estas costas, de los que ni siquiera la capital del partido, con sus defensas urbanas y su alcazaba, escapó a este hecho. A mediados del siglo XVI volvieron a intensificarse las incursiones berberiscas y, tras el levantamiento morisco acontecido entre 1568-1571, se producirían nuevos ataques apoyados por el imperio otomano, que se prolongaron hasta principios del siglo XVII, una vez se había producido en 1609 la expulsión definitiva de los moriscos de la Península Ibérica. La existencia de topónimos en el término municipal veleño como Barranco del Turco, situado entre la Torre del Jaral y la Torre de la Boca del río Vélez, podría obedecer a este hecho.

La amenaza que supuso la piratería en el Mediterráneo originó un vacío poblacional en el litoral costero en la Edad Media y en Época Moderna. Así, tras el abandono de la población andalusí de las alquerías más cercanas a la costa en el siglo $\mathrm{XV}$, fue difícil fijar a los colonos cristianos tras el reparto de estas tierras. Para solventar dicho peligro, se rehicieron y mejoraron constantemente las fortificaciones existentes, creándose toda una red de torres vigías (Fig. 3) (Capilla Luque, 2008; Gil Albarracín, 2004), quedando en el interior las torres que estuvieron asociadas a alquerías, a recursos naturales y/o a vías de comunicación.

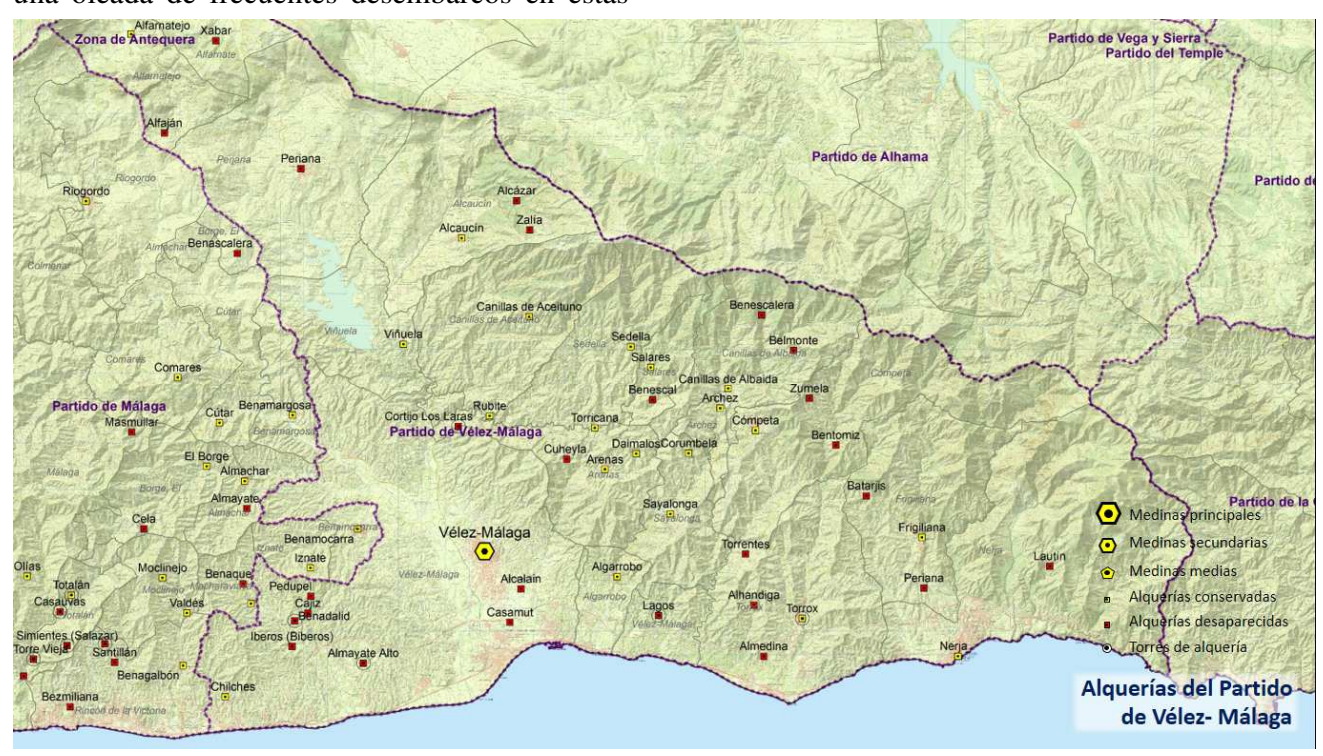

Fig. 2. Ubicación de las distintas unidades de población en el territorio vinculado a Vélez-Málaga al final de la Edad Media. 


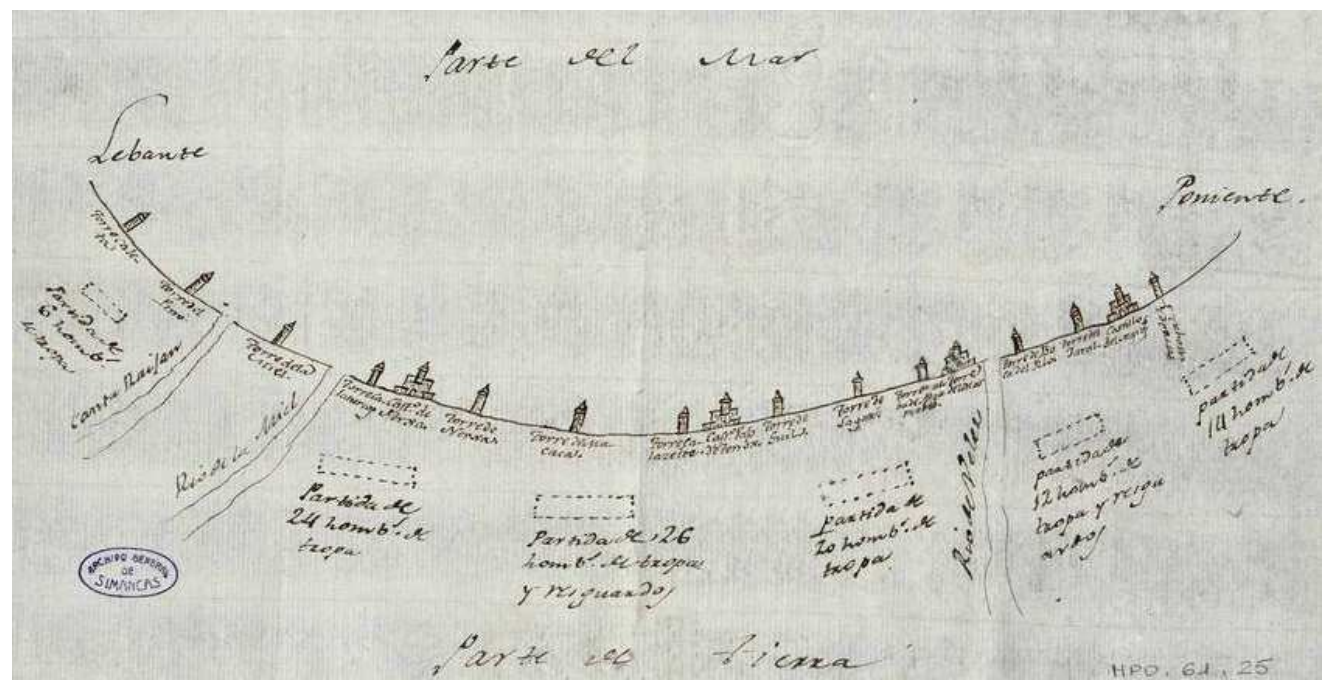

Fig. 3. Borrón de las Playas del Partido de Vélez-Málaga (1797). Archivo General de Simancas, MPD, 61, 025. De izquierda (levante) a derecha (poniente) se indican las siguientes defensas: Torre de la Caleta, Torre del Pino, Torre de la Miel, Torreta de Maro, Castillo de Nerja, Torre de Nerja, Torre de Macaca, Torre de Calaceite, Castillo Bajo de Torrox. Torre de Güi, Torre de Lagos, Torre Nueva de Algarrobo, Torre del Mar, Torre de la Boca del Río (Manganeta), Torre del Jaral, Castillo del Marqués y Torre de Moya.

\section{Torres de alquería}

En el siglo XIII se habría consolidado ya una red de estas alquerías, concentradas especialmente en la zona occidental de Vélez-Málaga, que se convirtieron en los núcleos humanos fundamentales para la explotación agrícola del medio. Tal habría sido el caso de Almayate, Benamocarra, Benajarafe, Pedupel, Benadalid, Cajíz, Íberos, Iznate, Torrentes, Alcalaín...

De entre la más de 40 que se han podido documentar en el territorio veleño, en las más inmediatas a la costa (Lagos, Almayate, Benadalid, Lagos, Torrox, Nerja...) llegaron a constituirse elementos defensivos que pudieron contar con una torre y/o un recinto asociado. De entre ellas, una de las más cercanas a Vélez-Málaga fue la de Almayate, cabeza de un distrito situado entre la Axarquía malagueña, la tierra de Comares, el río de Vélez y el mar (Martín Córdoba, et al., 2005, pp. 53-67; Pezzi Cristóbal, 2005, pp. 437454). Estaría desarrollada en torno al Arroyo de la Acequia, que desemboca en el Mediterráneo entre el Castillo del Marqués y la Torre del Jaral. Contaba con fértiles huertas regadas por acequias y norias que llegaban prácticamente hasta la playa de las Huertas de Almayate (en la actualidad, de Valle-Niza).

La importancia tanto demográfica como económica de la zona quedó reflejada en las visitas del reformador Alfonso Se-rrano, quien, en su inspección realizada entre 1496 y 1498, indicó que la alquería de Almayate constaba de 179 casas, frente a las 54 de Iznate y las 21 de Cajiz.

El 11 de mayo de 1487, dos semanas después de que Vélez-Málaga capitulara, el rey Fernando concedió a los pobladores de Almayate un seguro real por el que, excepcionalmente, se les permitía quedarse a vivir en sus casas y conservar todas sus propiedades de por vida, pero no heredables. Fue reconvertida en villa en 1491 y, en febrero de 1496, la Corona amplió el seguro a todos los descendientes, a cambio de que los vecinos mudéjares contribuyeran a costear la defensa costera y construyeran una nueva torre vigía en el Peñón de Almayate, conocida como Torre de Moya desde mediados del siglo XVI (Capilla Luque, 2013, pp. 57-64; Mayorga Mayorga, 2005, p. 2375).

Entre 1506 y 1507 los moriscos de Almayate huyeron a Berbería y este suceso fue aprovechado por Íñigo López de Mendoza, Capitán Gene- 
ral del reino de Granada, para pedir a la Corona la cesión de dicho lugar, merced que le fue otorgada el 28 de octubre de 1508 , obteniendo autorización para repoblar el lugar con sesenta vecinos moriscos. También obtuvo la posesión de la fortaleza, que usó como almacén de las rentas en especie (Szmolka Clares, et al., 1996, pp. 442, 659), siéndole concedida la tenencia de la misma en 1513 (Capilla Luque, 2013, pp. 57-58).

Esta alquería poseía una fortificación, cuya alcaidía había sido concedida inicialmente por los Reyes Católicos a Gonzalo de Cortina, repartidor de Vélez-Málaga. Se trataría de una torre rodeada por una cerca que tenía en su interior las ruinas de una mezquita, cuyos materiales habían sido aprovechados por los vecinos mudéjares para construir en 1497 la torre costera a la que se habían obligado.

Los restos de la fortaleza de Almayate, se conservan en la parte superior de un pequeño promontorio situado a unos 95 m.s.n.m., a poniente y a menos de $100 \mathrm{~m}$ del lugar de La Ermita, junto al camino procedente de Benaque, Macharaviaya, Iznate y Cajiz y que se dirige hacia la desembocadura del río Vélez.

Las fases cronológicas que se han podido documentar se encuadran en la última época nazarí, aunque los restos cerámicos dispersos por el solar indican periodos de ocupación desde el periodo almohade hasta principios de la Edad Moderna (Mayorga Mayorga, 2005, pp. 23752378).

\section{Torres vigías de origen andalusí}

Ninguna de las que se han conservado en la costa pueden adscribirse completamente a ese momento, pero, de la Instrucción de 1497 y en la Provisión de 1501, emitida por los Reyes Católicos para la defensa de la costa del Reino de Granada, se desprende que, tanto, la Torre de Chilches (Ruiz Povedano, 1974, pp. 27-28), como la Torre del Mar y la Torre del Jaral (Gil Albarracín, 2004), tuvieron una construcción previa en dicha localización. De entre ellas, ésta última es la que tipológica y morfológicamente puede adscribirse a una época más antigua. Está situada en un acantilado a unos 46 m.s.n.m. y es la única de la costa de la Axarquía que tiene planta rectan- gular, con unas medidas aproximadas en la base de 5,30 x 3,80 m y con una altura de unos 10,20 $\mathrm{m}$.

Presenta un cuerpo inferior macizo con una cámara superior, cuyo acceso se abre en su cara norte a partir de los $6 \mathrm{~m}$. El terrado presenta un pretil con diversas aberturas que pudieron estar relacionadas con primitivos matacanes, destacando el que estuvo sobre el acceso.

$\mathrm{Al}$ nordeste de la torre, a unos $20 \mathrm{~m}$ de su base, se han conservado restos de estructuras murarias que podrían corresponder a la estancia de los torreros. Sin embargo, no es posible localizar indicios de pozos o manantiales inmediatos para su abastecimiento de agua, hecho que resulta común a otras torres vigías en altura.

Se han conservado tres atalayas que estuvieron vinculadas y sirvieron para señalar el límite del territorio de Vélez-Málaga. Estuvieron situadas en el Cerro del Tambor (549 m.s.n.m.), en el Cerro de la Torre (554 m.s.n.m.) y en el Cerro de la Atalaya (458 m.s.n.m.).

Destaca ésta última por los restos que aun presenta (Fig. 4). Se localiza por encima de los caseríos de Aldea Alta y Aldea Baja, a 2,40 km al sur-suroeste de la localidad de La Viñuela, en el límite con el término municipal de VélezMálaga.

Formaba parte del sistema de comunicaciones entre la costa y el Castillo de Zalía, facilitando la conexión visual con la Alcazaba de VélezMálaga. Está construida con piedra pizarra, formando hiladas irregulares tomadas con mortero de cal. Tiene unos $10 \mathrm{~m}$ de altura conservados y contó con una ménsula de piedra del matacán que defiende una puerta, situada a unos $6,50 \mathrm{~m}$, ocultando una bóveda de ladrillos medio destruida.

Fue una de las pocas torres del interior que siguió siendo utilizada en el siglo XVI sin ser parcial o totalmente demolida, dado que controlaba el paso natural que se abría entre Málaga y Granada por el Boquete de Zafarraya. La parte superior, que presenta un ligero talud hacia el interior, había sido rehecha y recrecida en este momento (Martín García, Aguilera Peragalo, 2004, pp. 58-59). 


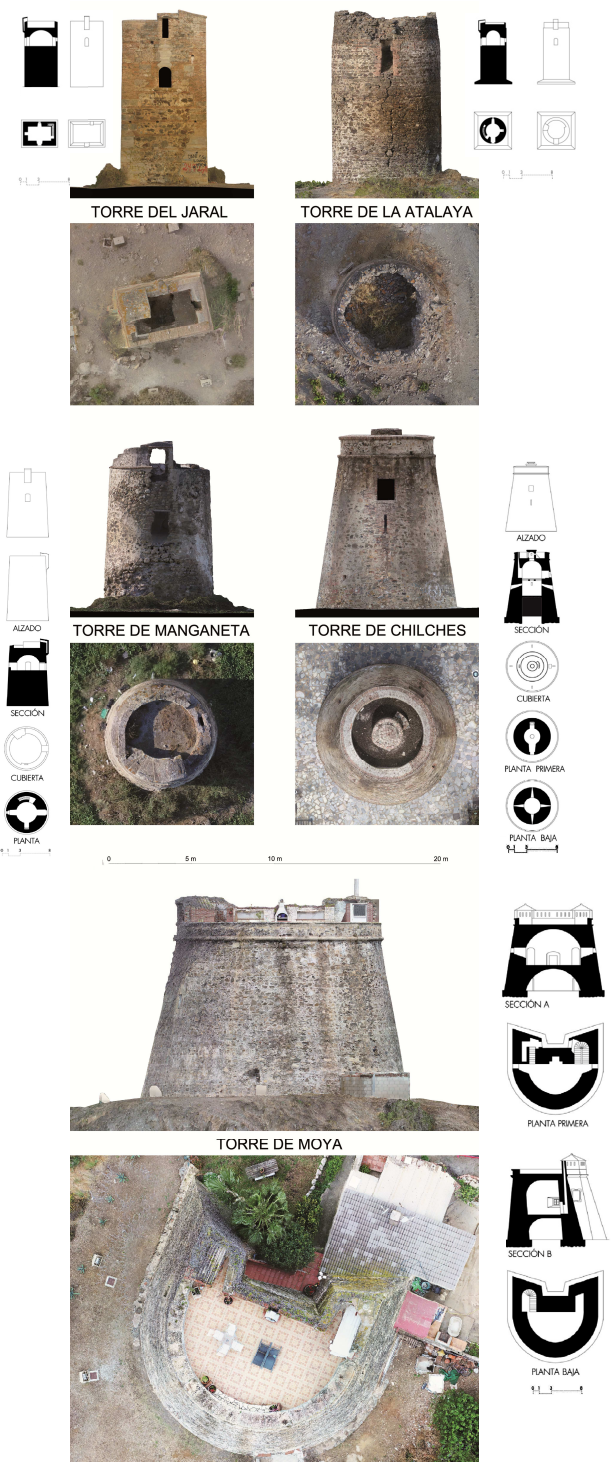

Fig. 4. Tipologías de torres defensivas existentes en el territorio de Vélez-Málaga.

\section{Atalayas construidas en el siglo XVI}

Se trata de estructuras cilíndricas con talud poco acusado. De entre ellas destaca la Torre de Manganeta (Fig. 4), que se encuentra en la zona de los Toscanos. Se levanta cerca de la margen derecha de la desembocadura del río VélezMálaga, en una zona completamente llana, a unos 5 m.s.n.m., hoy separada de la línea costera unos $700 \mathrm{~m}$ como consecuencia del avance del delta.

Se encuentra a unos $3,35 \mathrm{~km}$ al este de la Torre del Jaral y no hay obstáculos importantes que dificulten su visión, hecho que sí ocurre respecto de la Torre del Mar, situada a $2 \mathrm{~km}$ a levante, aunque mantiene enlace óptico con la Torre Ladeada de Algarrobo, ya a 5,80 km.

Tiene $5 \mathrm{~m}$ de base y un perímetro de más de 20 $\mathrm{m}$, con una altura que se eleva por encima de los $9 \mathrm{~m}$. Cuenta con un cuerpo inferior macizo y una cámara superior con el acceso en el lado sur, presentando aberturas en los lados norte y este, y chimenea con su correspondiente salida de humo en el terrado. La puerta queda situada a $4 \mathrm{~m}$ del suelo, aunque la torre puede tener parte de su alzado enterrado.

\section{Torres vigías construidas en el siglo XVIII}

\subsection{Atalayas troncocónicas}

Entre ellas, se han conservado la Torre de Chilches (Fig. 4) y la Torre de Lagos (Fig. 5). Ésta última se ubica frente al Cerro de la Molineta, en un acantilado a unos 46 m.s.n.m., situado al este de la rambla del río Lagos, donde ya se podrían haber ejercido labores de vigía durante el período andalusí, situándose a tan solo $1,33 \mathrm{~km}$ de la Torre del Güi (Torrox) y a 3,50 km de la Torre Ladeada (Algarrobo), con la que no tiene visión óptica. En la Instrucción de los Reyes Católicos para la defensa de la costa del Reino de Granada de 1497 se indicó que era una estancia del término de Vélez-Málaga. en la que habían de hacer una torre los mudéjares de Benamocarra, Carcis, Santillana y Pedaupel, con la ayuda de los de Lagos.

La torre primigenia había sido construida en el siglo XVI con forjados de madera que fueron incendiados por los moriscos durante el levantamiento de 1568-1571. En la Relación de la visita de Antonio de Berrio y Luis Machuca a la costa del reino de Granada por orden del Duque de Arcos, se indica que permaneció despoblada hasta principios de julio de ese último año.

La atalaya que se ha conservado habría sido construida en la segunda mitad del siglo XVIII 
siguiendo el modelo de atalaya troncocónica establecido por José Crame en 1765 (Fig. 5). Cuenta con una altura de 9,50 m, con $8,60 \mathrm{~m}$ de diámetro y un perímetro en su base de $27 \mathrm{~m}$.

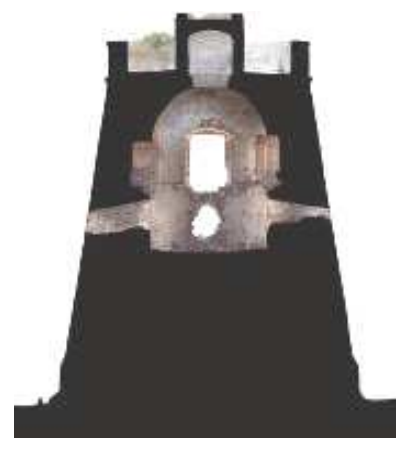

Fig. 5. Sección oeste-este del estado actual de la Torre de Lagos.

Su puerta se encuentra a unos $5 \mathrm{~m}$ del suelo y el interior presenta una cámara subdividida en dos pisos, contando el inferior con cuatro puntos de luz que corresponderían con otras tantas fusileras. El piso superior presenta la entrada y la chimenea con salida de humo al terrado. Este último posee en el centro un cuerpo de forma cilíndrica, donde se produciría la señal luminosa nocturna a la manera de una almenara.

A la cámara superior, que albergaba al vigilante, se accedía mediante escala o escalera a través de un gran vano con arco escarzano abierto en altu$\mathrm{ra}$, orientado al norte. Al terrado se accedería por medio de una escalera de la que se han conservado los huecos de apoyo en el anillo que conforma el óculo de la cúpula interior, que tendría protegida su salida al exterior con una pequeña torreta de planta circular situada en el centro. Aquél se cierra mediante un pretil que hace funciones de parapeto, resaltado con dos hiladas de ladrillo dispuestos en vertical a tizón, la superior de lados planos y la inferior redondeados.

Contó con una garita elevada sobre el nivel de la azotea, a la manera de los matacanes de las torres de siglos anteriores, hoy desmochada a nivel del suelo de guardia. El hueco que presenta hacia el lado sur no corresponde a la presencia de otro matacán, sino que es una erosión reciente de la sección más débil de la torre, aquella que co- rresponde al tiro de la chimenea, que se desarrolla en el interior del muro sur.

Presenta un revoco exterior sobre el que se aplicaron fajas de encintado siguiendo líneas paralelas y otras oblicuas, con despiece en espiga.

\subsection{Baterías para 2 cañones con hornabeque}

La Torre Moya (Fig. 4) se encuentra emplazada a 39 m.s.n.m., a unos 3,33 km al este de la Torre de Chilches y a $2,43 \mathrm{~km}$ del Castillo del Marqués. Fue situada sobre un promontorio de 39 m.s.n.m., referido en los documentos de finales del siglo XV como Peñón de Almayate.

La que nos ha llegado habría sustituido a aquella que habrían construido los mudéjares de Almayate en 1597. Se trata de una batería semicircular para 2 cañones orientada hacia el mar, prolongada al norte con dos espolones oblicuos en el dorso a la manera de hornabeques, rematados mediante torretas con fusileras que habrían estado cubiertas con teja curva. Consta de dos plantas y una azotea, protegida en su lado sur, señalado al exterior mediante un pretil y, en su base, una moldura de bocel que recorre todo el perímetro de la torre, muy similar al existente en el Fuerte de Bezmiliana del Rincón de la Victoria.

Tiene un perímetro aproximado de $53 \mathrm{~m}$ y una altura de $11 \mathrm{~m}$, con un muro de más de $2 \mathrm{~m}$ de grosor en la planta baja, que se estrecha en altura. La puerta se encuentra a $6 \mathrm{~m}$ del suelo en el lado oriental del espigón derecho, al que se accede mediante una escalera construida en el siglo $\mathrm{XX}$, protegida por varias fusileras situadas en frente. Bajo esta sala, se halla el sótano o Santa Bárbara, con un polvorín rectangular en la esquina nordeste, separado por un muro curvo.

\section{Conclusiones}

El término municipal de Vélez-Málaga constituye un buen ejemplo dentro de la costa meridional española en lo referente a la conservación de distintos elementos fortificados de diferentes cronologías. Las torres presentan un amplio repertorio en el que se pueden encontrar las tipologías más características desarrolladas entre la Edad Media y el siglo XVIII, desde las atalayas de sección cuadrangular o cilíndrica con poco ta- 
lud, hasta las troncocónicas con escarpe acusado y los baluartes artilleros semicirculares con hornabeque a sus espaldas.

Mientras que los sistemas defensivos de algunas alquerías nazaríes y del territorio veleño pudieron haber sido establecidos a partir del siglo XIV frente a la creciente amenaza castellana en las zonas fronterizas terrestres y marítimas, tras la conquista, la frontera se desplazó a la costa. En la decisión del emplazamiento de las torres vigías se priorizaron las cuestiones de visibilidad y control territorial. Así, junto a las atalayas más elevadas no se localizan manantiales de agua, canalizaciones hidráulicas o pozos, lo que parece indicar que no fue éste el motivo principal para su emplazamiento. En las que se situaron en las vegas o ramblas, la obtención de agua podría haber sido más fácil por medio de pozos excavados en los terrenos aluviales, pero tampoco se han conservado estas infraestructuras, en el caso de que hubieran existido.

El estudio de la implantación y la materialidad constructiva de estas torres, permite entender los procesos defensivos llevados a cabo en estas costas, generalmente asociados a los momentos de mayor inestabilidad bélica.

\section{Agradecimientos}

Este trabajo ha sido realizado en el marco del Proyecto I+D+i "Las atalayas que defendieron el reino de nazarí de Granada. Análisis y documentación científica (Nazalaya)" (Programa Estatal de Fomento de la Investigación Científica y Técnica de Excelencia del Ministerio de Economía, Industria y Competitividad, HAR201679689-P, 2017-2020), convocatoria de 2016, cofinanciado con fondos FEDER. El estudio de las torres conservadas en este término municipal ha permitido la realización de la diagnosis de estas torres dentro del programa de arquitectura defensiva del Excmo. Ayuntamiento de VélezMálaga (EDUSI O.T.6 - 0.E.6.3.4 Rehabilitación y Promoción del Patrimonio Histórico, VM-OT6-LA1).

\section{Bibliography}

Capilla Luque, F. (2008). Las fortificaciones del partido de Vélez-Málaga entre los siglos XV al XIX, Tesis Doctoral (inédita), Universidad de Málaga, Málaga.

Capilla Luque, F. (2013). "Las fortificaciones de Almayate", Boletín de la Sociedad de Amigos de la Cultura de Vélez-Málaga, 12, pp. 57-64.

Falcón Márquez, T. (1989). Torres de almenara del Reino de Granada en tiempos de Carlos III, Junta de Andalucía, Consejería de Obras Públicas y Transportes.

Galán Sánchez, Á. (1984). "La Alquería de Almayate (1487-1507): ensayo para un modelo de "resistencia pasiva" en el Reino de Granada", Actas del III Simposio internacional de mudejarismo, Teruel, pp. 93-110.

Gil Albarracín, A. (2004). Documentos sobre la defensa de la costa del Reino de Granada (1497-1857), Ed. Griselda Bonet Girabet, Almería-Barcelona, pp. 270-271; 325-326; 389-391; 491-492; 505-506.

Martín García, M.; Aguilera Peragalo, L.M. (2004). "Torres atalayas del interior de la provincia de Málaga”, Castillos de España, 134-135, pp. 51-60.

Mayorga Mayorga, J. (2005). "Despoblado de Almayate Alto (Vélez-Málaga, Málaga)”, Anuario Arqueológico de Andalucía, Málaga, pp. 2375-2378.

Suberbiola Martínez, J. (1991). "El seguro real de Almayate (1487-1497)”, Baetica, 13, pp. 193-216. 